\title{
Mantle flow drives the subsidence of oceanic plates
}

\author{
Claudia Adam, ${ }^{1,2}$ Valérie Vidal $^{3}$ \\ ${ }^{1}$ Institute for Research on Earth Evolution, Japan Agency for Marine-Earth Science and \\ Technology, 2-15 Natsushima, Yokosuka, 237-0061, Japan. \\ ${ }^{2}$ Centro de Geofísica, Universidade de Évora, Colegio Luis Verney, Rua Romão Ramalho \\ 59, 7002-554 Évora, Portugal. \\ ${ }^{3}$ Laboratoire de Physique, Université de Lyon, Ecole Normale Supérieure de Lyon - CNRS, \\ 46 Allée d'Italie, 69364 Lyon cedex 07, France.
}

The subsidence of the seafloor is generally considered as a consequence of its passive cooling and densifying since its formation at the ridge and thus, as a function of lithospheric age only. However, the lithosphere is defined as the thermal boundary layer of mantle convection, which should thus determine its structure. We examined the evolution of the lithosphere structure and depth along trajectories representative of the underlying mantle flow. We show that along these flow lines, the seafloor depth varies as the square root of the distance from the ridge - as given by the boundary layer equation - along the entire plate, without any flattening. Contrary to previous models, no addidional heat supply is required at the base of the lithosphere.

At mid-oceanic ridges, hot material rises and then cools while driven away to subduction zones, forming the tectonic plates. The structure of the lithosphere, as the upper thermal boundary layer, is determined by conductive cooling after its formation at the 
ridge. The lithosphere thickens away from the mid-oceanic ridge and, as rock density increases by cooling, it slowly sinks into the underlying mantle. The seafloor depth is thus regarded as a function of its age only and, therefore, studied along trajectories following an age gradient (referred to as 'age trajectories'). Several models have been proposed to describe the thermal subsidence of the seafloor with age (1-4), but no consensus has been reached on the origin of the flattening observed at old ages (5). These thermal subsidence models do not directly consider the role of convection in the underlying mantle, which deforms with a velocity on the order of a few centimeters per year. In particular, their description of passive lithosphere cooling ignores any change in plate motion - in other words, in mantle convection.

The first model that proposed to explain the variations of seafloor depth with age the half-space model $(6)$ - considered the lithosphere as the cold upper boundary layer of a cooling mantle, where the depth varies with the square root of the distance from the ridge. By assuming a constant plate velocity, the seafloor depth therefore varies with the square root of the age of the lithosphere. However, subsequent studies found that the observed seafloor depth at old ages (>70 Ma) was significantly shallower than the model prediction $(1,2)$. They suggested that the flattening observed at old ages could be accounted for by using a model in which the lithosphere is considered as a rigid, cooling conductive plate with a constant basal temperature (plate model) (2,3,7). However, if this constant temperature at the base of the plate is a simple and convenient way to introduce the additional heat supply necessary to explain seafloor flattening at old ages, there is no physical reason why this should be true for the entire plate. Different physical processes have been proposed to explain the origin of this additional heat supply: small-scale convection (8-11), upwelling mantle plumes (12-13), or internal heating, including radiogenic heating as well as the heating from secular cooling $(11,14)$. Nonetheless, which 
of these physical processes is really responsible for the observed flattening at old ages remains an open issue.

Previous global models also do not account for possible variations of ridge temperature and depth, either spatial or temporal. Systematic studies of seafloor subsidence along the East Pacific Rise (EPR), for instance, show that the ridge depth varies from 2000 to $3200 \mathrm{~m}$, and the associated subsidence rate from 50 to $450 \mathrm{~m} / \mathrm{Ma}^{1 / 2}(15-19)$. These variations imply spatial mantle temperature variations of about $\pm 100^{\circ} \mathrm{C}$ (16-18). Others suggested that the possible change through time of plate motion and plate-driving forces (20) [in particular, pulsations in seafloor spreading rates (21), and a higher mean mantle temperature during the Mesozoic (22)] could be responsible for higher ridge height and subsidence rate during this period. Estimates of a mantle $\sim 50^{\circ} \mathrm{C}$ warmer during the Mesozoic, for example, could explain much of the observed flattening relative to a boundary-layer model (22).

Regardless of their differences, all previous models are based on the hypothesis that the thermal structure of the oceanic lithosphere is determined entirely by its age - that is to say, the time elapsed since its creation at the mid-oceanic ridge. However, because mantle convection and plate motion evolve over time, the new thermal conditions imposed to the base of the oceanic lithosphere also change, thus modifying its structure. This lithospheric structure will evolve in order to adapt to the new thermal conditions imposed at its base, along the entire plate. After a drastic change in the convective system, it will either thicken (respectively thin) if the temperature at its base, defined by the new convective system, is cooler (respectively hotter) than previously. After a time long enough, the lithosphere will tend toward the structure of the thermal boundary layer for the new underlying mantle flow, independently of its initial state. 
In order to test that the structure of the oceanic lithosphere is indeed determined by the underlying mantle convection, we analyzed more than 770 depth profiles, leading to a complete coverage of the Pacific plate (23). Several kinematic models have been tested to compute the trajectories representative of the present-day mantle convection (flow lines) (23). The Pacific plate is an ideal candidate to test our hypothesis for a number of reasons. First, the Pacific plate velocity has remained constant over the last 47-50 Myr (24), providing sufficient time for the lithosphere to adapt to the new thermal conditions. Second, the drastic change in its motion, which is the consequence of a large-scale rearrangement of the mantle convection 47-50 Myr ago (24), has necessarily induced an important change in the thermal conditions applied to the older lithosphere. Therefore flow lines, representative of the underlying mantle convection, strongly differ from age trajectories. Third, the large size of the Pacific plate provides us with the longest observable oceanic lithosphere temporal and spatial evolution on the planet. Finally, due to the strong driving force provided by its slab morphology and trench length, the Pacific has the fastest plate velocity (25). If mantle convection is the driving mechanism of seafloor subsidence, its effects will be most visible over this plate.

Along the flow lines (Fig. 1), we observe a linear relationship between the seafloor depth $(z)$ and the square root of the distance from the ridge $\left(x^{1 / 2}\right)$, written as

$$
z=z_{R}+a x^{1 / 2}
$$

where $z_{R}$ is the ridge depth and $a$ the subsidence rate. This relationship holds true all along the plate, from the ridge where it forms, to the subduction zone where it sinks into the mantle. Departures from the linear trend are localized (Fig.1) and can be explained by local geophysical processes. The highs are associated with volcanoes (isolated seamounts, 
hotspot chains) and swells due to buoyant mantle upwelling (including the South Pacific Superswell). The lows are correlated either to the flexure of the lithosphere due to volcano loading, or to fracture zones. The wavelength of these anomalies is in all cases much shorter than the general trend (Fig.1).

Along the flow lines, no flattening is observed at old ages, far away from the ridge. Despite departures from the model due to local processes, the thermal subsidence along the present-day convective motion direction follows the expected trend. Over the Pacific plate, the flow lines strongly differ from the age trajectories (Fig.2), which represents the key point to discriminate our analysis from previous models. Along the age trajectories, the depth profiles represented in Fig.2 (based on a continuous grid (23)) show that there is an apparent flattening. But this latter is only due to the misleading direction along which the subsidence is investigated. Contrary to previous models $(2,3)$, our model fits the general trend of the bathymetry along the entire plate. The subsidence rates found in this study vary from 0.5 to $3.5 \mathrm{~m} / \mathrm{m}^{1 / 2}$. Rescaling by the constant Pacific plate velocity $\left(9 \mathrm{~cm} . \mathrm{yr}^{-1}\right)$ gives values ranging from 200 to $900 \mathrm{~m} / \mathrm{Ma}^{1 / 2}$, comparable to the values found in previous studies (15-19).

The general trend of the seafloor depth along flow lines, representative of the underlying mantle convection, validates our hypothesis, that the lithosphere should be viewed as the upper thermal boundary layer of mantle convection - its true definition (26). Due to the steady-state conditions imposed during the last 47-50 Myr (24), the Pacific lithosphere had time to readjust, by conduction, to the thermal conditions imposed at its base by the underlying convective mantle. The structure of the lithosphere, and hence its thermal subsidence, are therefore driven by the underlying mantle flow. This simple alternative perspective contrasts to the many more complicated explanations that have been 
proposed previously. In particular, we find that there is no seafloor flattening at old ages, and therefore no need to invoke any additional heat supply at the base of the old lithosphere.

\section{References and Notes}

1. J. G. Sclater, L. A. Lawver, B. Parsons, J. Geophys. Res. 80, 1031-1052 (1975).

2. B. Parsons, J. G. Sclater, J. Geophys. Res. 82, 803-827 (1977).

3. C. A. Stein, S. Stein, Nature 359, 123-129 (1992).

4. M.-P. Doin, L. Fleitout, Earth Planet. Sci. Lett. 142, 121-136 (1996).

5. M.-P. Doin, L. Fleitout, Geophys. J. Int. 143, 582-594 (2000).

6. R. L. Parker, D. W. Oldenburg, Nature 242, 137-139 (1973).

7. A. G. Crosby, D. McKenzie, J. G. Sclater, Geophys. J. Int. 166, 553-573 (2006).

8. B. Parsons, D. McKenzie, J. Geophys. Res. 83, 4485-4496 (1978).

9. D. A. Yuen, L. Fleitout, Nature 313, 125-128 (1985).

10. M. A. Eberle, D. W. Forsyth, Geophys. Res. Lett. 22, 473-476 (1995).

11. J. Huang, S. Zhong, J. Geophys. Res. 110, B05404 (2005).

12. W. Schroeder, J. Geophys. Res. 89, 9873-9883 (1984).

13. G. F. Davies, J. Geophys. Res. 93, 10467-10480 (1988).

14. G. F. Davies, M. A. Richards, J. Geol. 100, 151-206 (1992).

15. J. C. Marty, A. Cazenave, Earth Planet. Sci. Lett. 94, 301-315 (1989). 
16. B. Lago, A. Cazenave, J. C. Marty, Phys. Earth Planet. Int. 61, 253-259 (1990).

17. K. A. Kane, D. E. Hayes, J. Geophys. Res. 99, 21759-21777 (1994).

18. K. Perrot, J. Francheteau, M. Maia, C. Tisseau, Earth Planet. Sci. Lett. 160, 593-607 (1998).

19. J. R. Cochran, W. R. Buck, J. Geophys. Res. 106, 19233-19258 (2001).

20. C. P. Conrad, C. Lithgow-Bertelloni, J. Geophys. Res. 109, B10407 (2004).

21. S. R. Gaffin, B. C. O'Neill, Geophys. Res. Lett. 21, 1947-1950 (1994).

22. E. Humler, C. Langmuir, V. Daux, Earth Planet. Sci. Lett. 173, 7-23 (1999).

23. Materials and methods are available on Science online.

24. W. D. Sharp, D. A. Clague, Science 313, 1281-1284 (2006).

25. A. E. Gripp, R. G. Gordon, Geophys. Res. Int. 150, 321-361 (2002).

26. T. Turcotte, G. Schubert, Geodynamics, $2^{\text {nd }}$ Edition (Cambridge Univ. Press, 2002).

27. W. H. F. Smith, D. T. Sandwell, Science 277, 1956-1962 (1997).

28. R. D. Müller, W. R. Roest, J.-Y. Royer, L. M. Gahagan, J. G. Sclater, J. Geophys. Res. 102, 3211-3214 (1997).

29. The authors acknowledge A. Bonneville, F. Lucazeau and Y. Fukao for fruitful discussions. 


\section{FIGURE CAPTIONS}

Figure 1. Main panel: bathymetry of the Pacific plate (27) corrected for sediment loading and flow lines (23). Side panels: profiles along the flow lines; in black, seafloor depth as a function of the square root of the distance from the ridge; in red, linear trend $z \propto x^{1 / 2}$; in blue and green, models from (2) and (3), respectively. Arrows indicate the local geological features responsible for the departure from the linear trend (FZ for fracture zone).

Figure 2. Right panel: Seafloor age (28), flow lines (black lines) and age trajectories (white lines) (23). Left panel: depth profiles along the age trajectories. In black, seafloor depth as a function of the square root of the seafloor age; in red, our model; in blue and green, models from (2) and (3), respectively. The model (red line) fits the general trend of the bathymetry along the entire plate. Contrary to previous models, there is no need to invoke any flattening at old ages. 


\section{Figure 1}
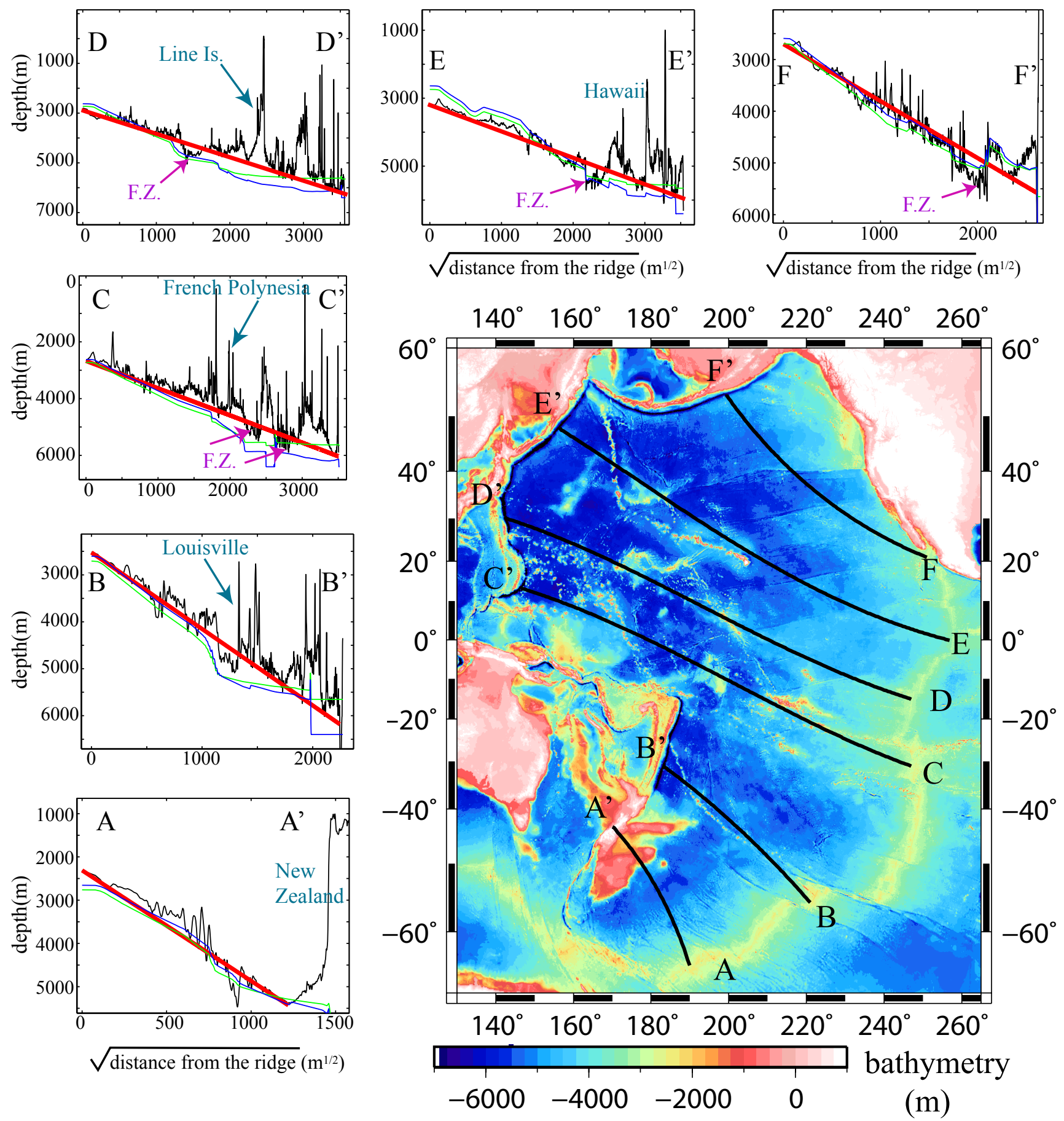
Figure 2

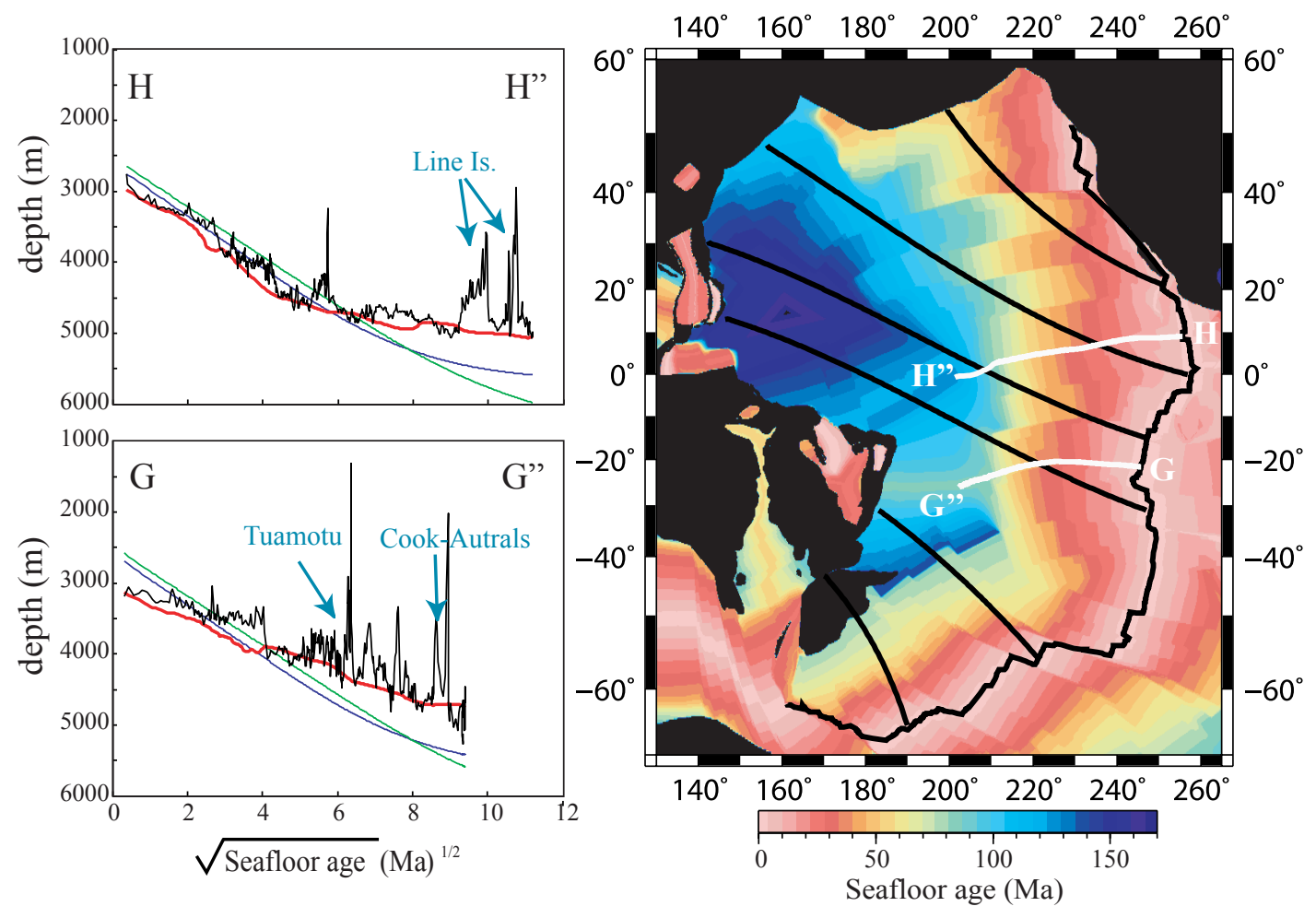

